\title{
Corrigendum
}

\section{Targeting BRAF in thyroid cancer}

\section{AV Espinosa, L Porchia and MD Ringel}

British Journal of Cancer (2007) 96, I3 I3. doi:10.1038/sj.bjc.6603676 www.bjcancer.com

(c) 2007 Cancer Research UK

Correction to: British Journal of Cancer (2007) 96, 16-20. doi: $10.1038 / 6603520$

The authors would like to note that the preliminary results of a phase II clinical trial of sorafenib in patients with metastatic thyroid cancer reported as a personal communication in the manuscript have been previously presented as part of the following two abstract presentations:

Kloos R, Ringel M, Knopp M, Heverhagen J, Hall N Weldy L, Arbogast D, Collamore M, Shah M (2005). Preliminary results of
Phase II clinical trial of RAF/VEGF-R kinase inhibitor, BAY 43-9006 (sorafenib), in metastatic thyroid carcinoma. Thyroid. 2005 Abstracts from International Thyroid Congress, Vol 15, No. S1:S-22.

Kloos R, Ringel M, Knopp M, Heverhagen J, Rittenberry J, Weldy L, Arbogast D, Collamore M, King M, Young D, Shah M (2006). Significant clinical and biologic activity of RAF/VEGF-R kinase inhibitor BAY-439006 in patients with metastatic papillary thyroid carcinoma (PTC): Updated results of a phase II study. J Clin Oncol, 2006 ASCO Annual Meeting Proceedings, Part I, Vol 24, No. 18S:5534. 